\title{
Welfare Implications of the Transition to High Household Debt*
}

\author{
Jeffrey R. Campbell ${ }^{\dagger}$ Zvi Hercowitz
}

November, 2006

\begin{abstract}
Aggressive deregulation of the mortgage market in the early 1980s triggered innovations that greatly reduced the required home equity of U.S. households. This allowed households to cash-out a large part of accumulated equity, which equaled 71 percent of GDP in 1982. A borrowing surge followed: Household debt increased from 43 to 62 percent of GDP in the 1982-2000 period. What are the welfare implications of such a reform for borrowers and savers? This paper uses a calibrated general equilibrium model of lending from the wealthy to the middle class to evaluate these effects quantitatively.
\end{abstract}

${ }^{*}$ We are grateful to Erik Hurst and Richard Rogerson for their discussions of an earlier version of this paper.

${ }^{\dagger}$ Federal Reserve Bank of Chicago and NBER. e-mail: jcampbell@frbchi.org

‡Tel Aviv University. e-mail: zvih@post.tau.ac.il

JEL Codes E44, E65

Keywords: Financial Reform, Mortgage Debt, Interest Rates 


\section{Introduction}

Who benefits the most from a reform which relaxes a binding borrowing constraint? Borrowers or savers? At the microeconomic level, only borrowers benefit because they are constrained. In other words, only for them the Lagrange multiplier on the constraint is positive. The macroeconomic interaction involves an additional consideration: Allowing larger borrowing raises the interest rate for while, i.e., the borrowers' terms of trade worsen for some time, and this redistributes the benefits. Hence, who gains the most is a quantitative issue.

The U.S. economy underwent a drastic reform of this type in the early 1980s. Most household debt in the United States requires an initial equity share in the home or vehicle that serves as collateral - a down payment - and a minimum rate of debt amortizationwhich determines the rate of equity accumulation. The Monetary Control and the Garn-St. Germain Acts of 1980 and 1982 allowed market innovations that dramatically reduced these equity requirements: Greater access to sub-prime mortgages, mortgage refinancing, and home equity loans, reduced effective down payments and increased effective repayment periods. More important for the short run, it enabled households to cash-out previously accumulated home equity, which in 1982 amounted to 71 percent of GDP. This was followed by a huge wave of household borrowing.

In this paper we focus on the welfare effects of such a reform using a calibrated model economy. The model is a general equilibrium framework for household borrowing from Campbell and Hercowitz (2006), which combines trade between a patient saver and an impatient borrower with equity requirements on housing and consumer durables typical of collateralized loan contracts. The model has a simple structure, but it captures the main features of the distribution of debt and financial assets across households in the US economy. Households in the first-to-ninth deciles of the wealth distribution owed 73.0 percent of total household debt in 1962, and 73.4 percent in 2001. Households in the tenth decile held 54.2 percent of total financial assets in 1962 and 72.8 percent in 2001. Hence, a large fraction of households owe debt to a small fraction of households. The model's equilibrium resembles this in an extreme way. The borrower owes all the debt to the saver.

With the model calibrated to the period prior to 1983, and the financial reform calibrated to the actual reduction of equity requirements on households, we compute the transition across the two corresponding steady states. Because the reform allows the borrower to cashout a large amount of accumulated equity, the equity constraint may not bind for some time. We use a modified version of the Fair-Taylor (1983) algorithm to solve the model, which determines when along the transition path the equity constraint binds. Across steady states, 
savers' welfare increases and borrowers' declines due to the higher debt. The borrowers' gains can accrue only during the transition.

The model's transition starts off with previously constrained households cashing out some of the home equity in excess of the new lower requirement. This borrowing surge increases the interest rate. Over time, the debt stabilizes at a higher level while the interest rate returns gradually to it's steady state. This resembles the evidence on the comovement of household debt and interest rates since 1983 .

The welfare analysis of the calibrated economy indicates that both households gain in terms of discounted utility at the time of the reform, although the saver's gain is much larger than the borrower's. The borrowers' gain is due to high consumption and durable goods purchases during the period following the reform. Of course, accumulated debt implies that at the new steady state a borrower's utility flow is lower than at the starting steady state. The savers gains initially while the terms of trade changed in their favor, i.e., the interest rate is high, and moving to the new steady state with higher assets.

The paper proceeds as follows. The next section provides the institutional background for the analysis and Section 3 presents the model. The steady-state to steady-state comparison following the reform is addressed in Section 4. In Section 5 we report first the calibration of the model and then the computed transition process. It concludes with the evaluation of the reform's welfare effects. In Section 6 we discuss the actual evolution of household debt and interest rates. Section 7 presents an extension of the model with an irreversibility constraint on durable goods investment. We conclude in Section 8.

\section{Institutional Background}

Our analysis takes the institutions structuring the household debt market as determined by regulation, so we begin with a review of how these have changed since 1982. It is helpful to emphasize first one feature of this market that remains the same: Homes and vehicles collateralize most household debt. According to the 1962 Survey of Financial Characteristics of Consumers, homes and vehicles collateralized 85 percent of total U.S. household debt. The analogous percentage from the 2001 Survey of Consumer Finances was 90 percent. $^{1}$

From the middle 1930s until the early 1980s, 15 and 30 year amortized mortgages accounted for most of collateralized household debt. These required the home owner to take an initial equity share at the time of purchase and to accumulate further equity as the debt

\footnotetext{
${ }^{1}$ Details of these observations are provided in Campbell and Hercowitz (2006), Appendix A.
} 
amortizes. The implied forced savings reflected the desire of the Roosevelt administration to reduce the likelihood of a mass default of highly-leveraged mortgagees, as occurred at the beginning of the Great Depression. A host of financial regulations supported this policy. The most prominent gave tax incentives for Savings and Loan associations to finance home mortgage lending with demand deposits and protected this trade from other financial intermediaries. The volatile financial markets of the 1970's made these and other New Deal financial regulations untenable. Congress and Presidents Carter and Reagan responded with the Monetary Control Act of 1980 and the Garn-St. Germain Act of 1982. These led to an aggressive reorganization of the housing finance system. ${ }^{2}$

Instruments for avoiding forced saving existed before financial deregulation. One could cash-out previously accumulated home equity either by taking a second mortgage or homeequity loan or by refinancing the debt with a loan exceeding the current mortgage balance, but lack of competition in lending made these rare. Deregulation lowered the cost of these instruments for all financial intermediaries and households. Accordingly, household debt began to grow. The ratio of mortgage debt to the value of owner-occupied homes was 0.31 in 1982, 0.37 in 1990, and 0.42 in 1995. Since then, it has fluctuated around this higher level.

A more detailed appreciation of how deregulation affected home equity accumulation can be gained by examining how households structured their mortgage debts. Time-series observations on typical terms of first mortgages are available from the Federal Home Finance Board's Monthly Interest Rate Survey, but these provide an incomplete picture because they ignore subordinated debt used to lower the effective down payments. Hence, we proceed by examining households debts in the Survey of Consumer Finances. Understanding that deregulation had the potential to vastly change households' financial decisions, the Federal Reserve Board resurrected its Survey of Consumer Finances program in the early 1980s, which collected the first "modern" SCF data set in 1983. ${ }^{3}$ The Federal Reserve carried out subsequent SCFs every three years. These surveys gathered detailed information on households' balance sheets and use of different financial instruments and institutions, so they

\footnotetext{
${ }^{2}$ Green and Wachter (2005) provide a history of New Deal mortgage institutions and of the process of dismantling them in the early 1980's. See also Florida (1986) and the articles contained therein.

${ }^{3}$ The code book to the 1983 SCF (written initially in 1985) begins "There have been many changes in financial markets during the last decade. Inflation and interest rates increased sharply in the late 1970s and then fell after recessions in 1980 and 1981-82. Major financial innovations occurred, such as the introduction of money market funds, and the regulation of financial markets altered dramatically after enactment of the Depository Institutions Deregulation and Monetary Control Act of 1980. To assess the effects of these changes on the financial position of households, the Board of Governors of the Federal Reserve System (and other agencies) joined together to sponsor the 1983 Survey of Consumer Finances (SCF)."
} 


\begin{tabular}{c|cc}
\multicolumn{2}{|c}{$\begin{array}{c}\text { Percent of Mortgagees } \\
\text { Year }\end{array}$} & $\begin{array}{c}\text { Average Equity/Value } \\
\text { at Purchase }\end{array}$ \\
\hline 1983 & 9.9 & 22.6 \\
1989 & 21.2 & 23.4 \\
1992 & 33.0 & 20.9 \\
1995 & 40.9 & 16.9 \\
1998 & 42.3 & 16.4 \\
2001 & 44.4 & 16.4
\end{tabular}

Table 1: Mortgage Terms and Instruments from the Survey of Consumer Finances

provide the data required for tracking the effects of deregulation on households' mortgage borrowing decisions.

For six SCFs, Table 1 reports two key summary statistics characterizing households' mortgage borrowing, the percentage of mortgagees who have refinanced the mortgage on their current residence, and the average home equity to value ratio for new home purchases. The first survey considered is that of 1983, which was collected only shortly after the GarnSt. Germain Act became law in October 1982. We consider these observations as indicative of mortgage borrowing just before deregulation's completion. We do not report results from the $1986 \mathrm{SCF}$, because of its problematic sampling procedure. ${ }^{4}$ The other surveys we do use are from 1989, 1992, 1995, 1998, and 2001.

Consider first the percentage of mortgagees who have ever refinanced. ${ }^{5}$ In 1983, approximately 10 percent of mortgagees had refinanced. By 1989, this had more than doubled, and it increased again to 33 percent in 1992. In 1995, it reached almost 41 percent, and it was slightly higher than that in 1998 and 2001. Hence, mortgage refinancing went from atypical to commonplace in about 12 years.

The final column reports the ratio of home equity to home value for newly purchased homes. ${ }^{6}$ These homes' owners have had very little time to accumulate equity through debt

\footnotetext{
${ }^{4}$ To create a panel data set, the 1986 survey sampled households living in the same housing units as the respondents to the 1983 survey. This non-standard sampling makes the resulting observations not representative of the U.S. population in that year

${ }^{5}$ We identify these households by comparing the year of home purchase with the year their oldest mortgage debt was issued.

${ }^{6}$ For the $1983 \mathrm{SCF}$, we defined a newly-purchased home as any home purchased in 1982 or 1983 . For the other surveys, all such homes were purchased by their current occupant in the survey year. The values reported equal the averages of this ratio across all such homes with mortgage debt exceeding 50 percent of
} 
amortization, so these ratios are very close to the homeowners' effective down payments. We expect deregulation to lower down payments, because it allowed lenders to more easily issue second or third mortgages when closing the home purchase. Because of these widespread options, down payments on individual mortgages after deregulation do not provide information about the effective initial equity shares. In 1983, this ratio equalled 22.6 percent. Although it changed little through 1992, it dropped four percentage points between 1992 and 1995 (to 16.9 percent). In the 1998 and 2001 surveys it equaled 16.4 percent.

These figures reflect the substantial changes in homeowners' financing options after deregulation. Refinancing became cheaper and thus also more widespread, and typical down payments on new homes fell considerably although with a delay of about ten years. We have also examined mortgagees use of home-equity lines of credit. Total debt incurred with this instrument never exceeded 1.5 percent of mortgagees' home value. Explaining the timing and relative magnitudes of these institutional changes lies beyond the scope of this paper. Our analysis takes the reduced equity requirements for household debt as given and uses a quantitative general-equilibrium model to determine their implications for macroeconomic dynamics and market participants' welfare.

\section{The Model}

The model builds on the general equilibrium framework with household debt in Campbell and Hercowitz (2006). It combines financial trade between a patient saver and an impatient borrower with an equity requirement typical of collateralized loan contracts in the United States. The different rates of time preference generate intertemporal trade in the form of household debt owed by the borrower to the saver. Becker (1980) showed that there exists no steady-state with positive consumption by all households in a similar economy without constraints on debt. In our model, the equity requirement limits the borrower's debt, so both households have positive consumption in the steady state. The interest rate equals the saver's rate of time preference, and the equity requirement prevents the borrower from expanding debt without further purchases of durable goods.

We study the transition path from one steady state to another with a lower equity requirement. The borrower begins this transition with a large amount of equity no longer required for borrowing, so the equity requirement might not always bind.

This section presents preferences, production technology, and the constraints on trade

the home's value. 
between the two households. It concludes with a discussion of both households' utility maximization problems and the definition of a competitive equilibrium.

\subsection{Preferences}

The saver's and the borrower's preferences differ in two respects: The saver is more patient and does not work. The first assumption generates a concentration of assets in a relatively small number of households. This follows Krusell and Smith's (1998) use of heterogeneity in thrift to generate an empirically realistic wealth distribution. The second assumption simplifies the model along and unimportant dimension. Because there are few savers and because they should each enjoy some of their wealth in the form of leisure, we expect them to contribute little to aggregate labor supply. Accordingly, abstracting from the saver's labor supply choice does not substantially alter the results. ${ }^{7}$

The borrower's and the saver's utility functions are:

$$
\begin{aligned}
& \sum_{t=0}^{\infty} \hat{\beta}\left[\theta \ln \hat{S}_{t}+(1-\theta) \ln \hat{C}_{t}+\omega \ln \left(1-\hat{N}_{t}\right)\right], \quad 0<\theta<1, \omega>0, \\
& \sum_{t=0}^{\infty} \tilde{\beta}\left(\theta \ln \tilde{S}_{t}+(1-\theta) \ln \tilde{C}_{t}\right),
\end{aligned}
$$

where $\hat{\beta}<\tilde{\beta}$. In (1), $\hat{S}_{t}, \hat{C}_{t}$, and $\hat{N}_{t}$ are the borrower's stock of durable goods-assumed to be proportional to the service flow - its consumption of non-durable goods and labor supply. In $(2), \tilde{S}_{t}$, and $\tilde{C}_{t}$ are the saver's consumption of the two goods. We use $\hat{A}$ and $\tilde{A}$ to represent borrower and saver specific versions of $A$ for the remainder of the paper.

\subsection{Technology}

The aggregate production function is $Y_{t}=K^{\alpha} N_{t}^{1-\alpha}$, where $0<\alpha<1, Y_{t}$ is output, $K$ is a constant capital stock, and $N_{t}$ is labor input. We discuss the implications of allowing for productive capital accumulation below in Section 8 .

The households can use output for either non-durable consumption or durable goods purchases. That is, $Y_{t}=C_{t}+X_{t}$, where $C_{t}$ represents aggregate non-durable consumption and $X_{t}=S_{t+1}-(1-\delta) S_{t}$ is aggregate investment in the durable good, which depreciates at the rate $\delta$.

\footnotetext{
${ }^{7}$ When we endow savers with the borrowers' intratemporal preferences and calculate the steady state of the model calibrated as described below, savers choose to not work at all.
} 


\subsection{Trade}

All trade takes place in competitive markets. The households sell capital services at the rental rate $H_{t}$ and labor at the wage $W_{t}$ to the representative firm. They also trade in collateralized debt, which is the only available security. The households' outstanding debts at the end of period $t$ are $\hat{B}_{t+1}$ and $\tilde{B}_{t+1}$. We denote the corresponding gross interest rate with $R_{t}$, which adjusts every period.

\subsubsection{The Equity Requirement}

An exogenous equity requirement on collateral constrains debt. This mimics a typical feature of loan contracts in the United States: An equity share that starts from a positive level (the down payment) and increases over time (if debt amortizes more rapidly than the good depreciates). In the model, the parameters capturing this feature are $0 \leq \pi<1$, the initial equity share, and $\phi$, which governs the speed of subsequent equity accumulation. When a loan is collateralized by a durable good $j$ periods old, the required equity share at the beginning of the following period is

$$
e_{j}=1-\left(\frac{1-\phi}{1-\delta}\right)^{j}(1-\pi) .
$$

For newly purchased goods $(j=0)$, the equity share is $\pi$. As the good ages ( $j$ increases), the equity share converges to one when $\phi>\delta$, and stays constant when $\phi=\delta$. We call the case of $\phi>\delta$ accelerated amortization, because the equity share increases over time. When $\phi=\delta$ the equity share remains at its initial level because debt and durable goods depreciate at the same rate. The institutional background presented above suggests modelling deregulation by lowering the initial equity share with a drop in $\pi$ and lowering the rate of equity accumulation by bringing $\phi$ closer to $\delta$.

For a household with positive debt, the total amount of equity at the beginning of period $t+1$ is $(1-\delta) S_{t+1}-R_{t} B_{t+1}$, where the durable stock is adjusted for depreciation and the debt for accumulated interest. This household's required equity in durable goods sums the equity requirements on the (depreciated) goods of all ages from equation (3):

$$
(1-\delta) S_{t+1}-R_{t} B_{t+1} \geq(1-\delta) \sum_{j=0}^{\infty}(1-\delta)^{j} X_{t-j} e_{j} .
$$

Using the definition of $e_{j}$, (4) can be expressed as a repayment constraint.

$$
R_{t} B_{t+1} \leq(1-\delta)(1-\pi) \sum_{j=0}^{\infty}(1-\phi)^{j} X_{t-j}
$$


Here, a debtor's total liability cannot exceed a linear function of the value of the goods that collateralize it with coefficients which decrease with $\pi$ and $\phi$. If $\phi=\delta$, the right-hand side of $(5)$ reduces to $(1-\delta)(1-\pi) S_{t+1}$. In this case, the constraint is formally identical to that which Kiyotaki (1998) derives from an environment with costly repossession. We do not stress this interpretation of the constraint, because we assume that public policy decisions determined $\pi$ and $\phi$ rather than considerations of private contracting.

\subsection{Utility Maximization}

We now examine both households' utility maximization problems. For this, we conjecture that in equilibrium the saver owns all physical capital and the borrower's debt. With the proposed equilibrium in hand, verifying this is straightforward.

\subsubsection{The Borrower's Problem}

To formulate the borrower's utility maximization problem, it is helpful to first represent the equity requirement recursively. Define

$$
\hat{V}_{t+1}=(1-\delta)(1-\pi) \sum_{j=0}^{\infty}(1-\phi)^{j} \hat{X}_{t-j} / R_{t} .
$$

This is the maximum debt principle this household can carry out of period $t$. Multiplying $\hat{V}_{t}$ by $(1-\phi) R_{t-1} / R_{t}$ and subtracting the result from $\hat{V}_{t+1}$ yields

$$
\hat{V}_{t+1}=(1-\phi) \frac{R_{t-1}}{R_{t}} \hat{V}_{t}+\frac{(1-\delta)(1-\pi)}{R_{t}} \hat{X}_{t}
$$

That is, the limit to the borrower's debts evolves recursively. With this definition of $V_{t}$, the equity requirement becomes

$$
\hat{B}_{t+1} \leq \hat{V}_{t+1}
$$

Together, (7) and (8) represent the borrower's required equity in its durable goods stock.

Given $\hat{V}_{0}, R_{-1} \hat{B}_{0}$ and $\hat{S}_{0}$, the borrower chooses sequences of $\hat{C}_{t}, \hat{X}_{t}, \hat{N}_{t}$, and $\hat{B}_{t+1}$ and $\hat{V}_{t}$ to maximize the utility function in (1), subject to the sequence of budget constraints

$$
\hat{C}_{t}+\hat{X}_{t}+R_{t-1} B_{t}=W_{t} N_{t}+B_{t+1}
$$

and the sequences of constraints in (7) and (8). Denote the current-value Lagrange multiplier on (9) with $\Psi_{t}$. Expressing the Lagrange multipliers on (7) and (8) with $\Psi_{t} \Xi_{t}$ and $\Psi_{t} \Gamma_{t}$, then 
$\Xi_{t}$ and $\Gamma_{t}$ measure the value in units of either consumption good of marginally relaxing their associated constraints.

In addition to the three constraints and the transversality conditions,

$$
\lim _{t \rightarrow \infty} \hat{\beta}^{t} \Psi_{t}=\lim _{t \rightarrow \infty} \hat{\beta}^{t} \Psi_{t} \Gamma_{t}=\lim _{t \rightarrow \infty} \hat{\beta}^{t} \Psi_{t} \Xi_{t}=0,
$$

the optimality conditions for this maximization problem are

$$
\begin{aligned}
\Psi_{t} & =\frac{1-\theta}{\hat{C}_{t}}, \\
\Xi_{t} & =\Gamma_{t}+\hat{\beta} \frac{\Psi_{t+1}}{\Psi_{t}} \Xi_{t+1}(1-\phi) \frac{R_{t-1}}{R_{t}}, \\
\Gamma_{t} & =1-\hat{\beta} \frac{\Psi_{t+1}}{\Psi_{t}} R_{t}, \\
1-\Xi_{t} \frac{(1-\pi)(1-\delta)}{R_{t}} & =\hat{\beta} \frac{\Psi_{t+1}}{\Psi_{t}}\left[\frac{\theta}{1-\theta} \frac{\hat{C}_{t+1}}{\hat{S}_{t+1}}+(1-\delta)\left(1-\frac{\Xi_{t+1}(1-\pi)(1-\delta)}{R_{t+1}}\right)\right], \\
W_{t} & =\left(\frac{\varphi}{1-\theta}\right) \frac{\hat{C}_{t}}{1-\hat{N}_{t}} .
\end{aligned}
$$

The equity requirement alters the interpretation of the multiplier on the budget constraint. For an unconstrained household such as the saver, it equals the marginal value of permanent income. In (11), $\Psi_{t}$ represents the marginal value of additional current resources, because the borrower cannot freely substitute intertemporally.

In (13), $\Gamma_{t}$ equals the deviation from the standard Euler equation, the shadow value of borrowing at time $t$. It is positive if the equity constraint binds at $t$ and zero otherwise. Iterating (12) forward yields $\Xi_{t}$ as the present value expression of the current and future values of $\Gamma_{t}$. Hence, even if the equity constraint does not bind currently, i.e., $\Gamma_{t}=0, \Xi_{t}$ is positive if the constraint is expected to bind sometime in the future. This is because $\Xi_{t}$ equals the price of an asset that allows its holder to borrow today and in the future.

Equation (14) characterizes optimal durable good purchases. If the borrower's equity requirement never binds, then $\Xi_{t}=\Xi_{t+1}=0$ and (14) equates the purchase price of the durable good to its immediate payoff (the marginal rate of substitution between durable and non-durable goods) plus its discounted expected resale value. In the more relevant case where $\Xi_{t}$ and $\Xi_{t+1}$ are both positive, it has the same interpretation where the borrower's "purchase price" is $1-\Xi_{t}(1-\pi)(1-\delta) / R_{t}$. Because the durable good provides the household with $(1-\pi)(1-\delta) / R_{t}$ units - the allowed loan-to-value ratio of the "asset" mentioned above the borrower's effective price lies below the real resource cost of 1 . 
Equation (15) is the consumption-leisure condition. It has the usual form because it involves only intratemporal substitution, which financial market imperfections leave unchanged.

\subsubsection{The Saver's Problem}

The saver's utility maximization problem presents no novelties, but we present it here for the sake of completeness. Given the constant capital stock, $\tilde{K}$, the initial durable goods $\tilde{S}_{0}$, and the financial assets $-R_{-1} \tilde{B}_{0}$; the saver chooses sequences of $\tilde{C}_{t}, \tilde{X}_{t}$, and $\tilde{B}_{t+1}$ to maximize utility subject to

$$
\tilde{C}_{t}+\tilde{X}_{t}-\tilde{B}_{t+1}=H_{t} \tilde{K}-R_{t} \tilde{B}_{t}
$$

The right-hand side of (16) sums the sources of funds: Capital rental revenue, and the market value of household debt. The left-hand side includes the three uses of these funds: Non-durable consumption, purchases of durable goods, and saving.

Denoting the current-value Lagrange multiplier on (16) with $\Upsilon_{t}$, the problem's first-order conditions are

$$
\begin{aligned}
\Upsilon_{t} & =\frac{1-\theta}{\tilde{C}_{t}}, \\
1 & =\tilde{\beta}\left[\frac{\Upsilon_{t+1}}{\Upsilon_{t}}\left(\frac{\theta}{1-\theta} \frac{\tilde{C}_{t+1}}{\tilde{S}_{t+1}}+(1-\delta)\right)\right], \\
1 & =\tilde{\beta} \frac{\Upsilon_{t+1}}{\Upsilon_{t}} R_{t},
\end{aligned}
$$

Equation (18) is a typical condition for optimal durable goods purchases, and (19) is the standard Euler equation.

\subsection{Production and Equilibrium}

The standard conditions for profit maximization of the representative firm are

$$
\begin{aligned}
W_{t} & =(1-\alpha)\left(\frac{K}{N_{t}}\right)^{\alpha}, \\
H_{t} & =\alpha\left(\frac{K}{N_{t}}\right)^{\alpha-1} .
\end{aligned}
$$

Given the two households' initial stocks of durable goods, $\hat{S}_{0}$ and $\tilde{S}_{0}$, the stock of outstanding debt issued by the borrower and held by the saver, $B_{0}=\hat{B}_{0}=-\tilde{B}_{0}$, the predetermined 
interest rate, $R_{-1}$, and $\hat{V}_{0}$, a competitive equilibrium is a set of sequences for all prices and the borrower's, saver's, and representative firm's choices such that both households maximize utility subject to the constraints, the representative firm maximizes its profit, the two households' durable goods stocks evolve according to $\hat{S}_{t+1}=(1-\delta) \hat{S}_{t}+\hat{X}_{t}$ and $\tilde{S}_{t+1}=(1-\delta) \tilde{S}_{t}+\tilde{X}_{t}$, and the input, product and debt markets clear.

Before proceeding to apply the model, we wish to comment on the model's demographics. The model is written with one saver and one borrower, but we intend the saver to stand-in for the wealthiest ten percent of households while the borrower represents all others. Because both households' preferences are homothetic and the saver earns no labor income, we can show that increasing the number of borrowers while holding the aggregate time endowment constant has no impact on any equilibrium object except consumption per borrower. With this in mind, we maintain the simplifying convention of referring to "the" borrower and "the" saver.

\section{Steady State Analysis}

Comparison of the model's steady state with different values of $\pi$ and $\phi$ provides an insight into the long-run implications of changing the equity requirement and also guides the quantitative examination of the complete equilibrium path. Begin with the steady-state interest rate, which equals $R=\tilde{\beta}^{-1}$ from the saver's Euler equation. With this in hand, it follows that $\Gamma=1-\hat{\beta} / \tilde{\beta}$ and

$$
\Xi=\frac{\Gamma}{1-\hat{\beta}(1-\phi)}>0 \text {. }
$$

That is, the saver's rate of time preference determines the interest rate at a level below the borrower's discount rate; and the equity requirement limits the borrower's steady-state debt.

The interest rate, $\Xi$, and (14) together determine the steady-state value of $\hat{S} / \hat{C}$.

$$
\frac{\hat{S}}{\hat{C}}=\frac{\theta}{1-\theta} \frac{\hat{\beta}}{(1-\Xi(1-\pi)(1-\delta) / R)(1-\hat{\beta}(1-\delta))}
$$

Lowering $\pi$ and $\phi$ impacts $\hat{S} / \hat{C}$ through this shadow price. Consider first lowering $\phi$. This increases $\Xi$ and so shifts the borrower's consumption towards durable goods. Lowering $\pi$ leaves $\Xi$ unchanged but also has a positive impact on $\hat{S} / \hat{C}{ }^{8}$

\footnotetext{
${ }^{8}$ One question of possible interest that is tangential to this comparative steady-state analysis is "Which
} 
Because the equity requirement limits the borrower's debt, we can determine $\hat{B} / \hat{S}$ by solving for $\hat{V} / \hat{S}$ using (7) and equating $B$ with $V$. The resulting debt to value ratio is

$$
\frac{\hat{B}}{\hat{S}}=\frac{(1-\pi)(1-\delta)}{R} \frac{\delta}{\phi},
$$

which clearly decreases with both $\pi$ and $\phi$.

With these ratios in hand, we can determine the share of labor income spent on the borrower's consumption.

$$
\frac{\hat{C}}{W \hat{N}}=\frac{1}{1+(R-1) \frac{\hat{B}}{\hat{S}} \hat{\frac{S}{C}}+\delta \frac{\hat{S}}{\hat{C}}} .
$$

In turn this determines the borrower's hours worked, because the steady-state version of (15) can be rewritten as

$$
\frac{\hat{C}}{W \hat{N}}=\frac{1-\theta}{\varphi} \frac{1-N}{N} .
$$

The results above imply that the right hand side decreases with $\pi$ and $\phi$. Hence, $N$ increases with these parameters. Altogether, lowering equity requirements shifts the borrower's steadystate allocation away from leisure and nondurable consumption and towards durable goods.

We now proceed to consider the saver's steady-state consumption and wealth. Combining the borrower's steady-state labor supply with the firm's optimality conditions immediately yields $W$ and $H$. Because lowering $\pi$ and $\phi$ raises $N$, such a credit-market liberalization endogenously shifts factor prices in favor of the saver. The saver's steady-state income equals $R \hat{B}+H K$, which obviously increases as $\pi$ and $\phi$ fall. Therefore, lowering the equity requirement increases steady-state income inequality. This redistribution has direct implications for welfare: The saver is better off and the borrower is worse off in the new steady state. Of course, a steady-state welfare comparison abstracts from the principle reason borrowers find it attractive to expand debt after deregulation: They can increase current consumption and pay later. The next section lays the foundation for a complete welfare analysis by calculating the equilibrium transition path following a reduction of $\pi$ and $\phi$ in a calibrated version of the model.

household spends a greater fraction of income on durable goods?" They differ in two respects: The borrower discounts the future with a lower discount factor, and the borrower faces a lower "shadow price" of durable goods. The first difference lowers $\hat{S} / \hat{C}$ relative to $\tilde{S} / \tilde{C}$, while the second difference works oppositely. It is not hard to show that the first difference dominates the second, so that $\hat{S} / \hat{C}<\tilde{S} / \tilde{C}$. That is, although the ability to buy durable goods with credit induces the borrower to raise $\hat{S} / \hat{C}$, the borrower spends a greater fraction of income on nondurable consumption because she is impatient to receive the future utility from durable goods. 


\section{Quantitative Results}

We first describe the calibration of the model and the solution procedure, and then present the results.

\subsection{Calibration}

The calibration of the model is similar to Campbell and Hercowitz (2006). The production function elasticity $\alpha$ equals 0.3 . The depreciation rate $\delta$ is 0.01 , which is the appropriately weighted average of 0.003 for owner-occupied residences and 0.031 for automobiles. ${ }^{9}$ For the saver we chose $\tilde{\beta}=1 / 1.01$, so that the quarterly interest rate is 1.0 percent; for the borrower, we assign a relative impatience of 0.5 percent per quarter, i.e., $\hat{\beta}=1 / 1.015$. This degree of impatience is similar in magnitude to that used by Krusell and Smith (1998). They use three levels of time preference, with 0.72 percent between the two extremes.

The main aspect of the calibration is setting the values of $\pi$ and $\phi$ for the high- and lowrequirement regimes. This calibration is based on the following correspondence between the model and the data. The model's loan-to-value ratio at the steady-state $(1-\delta)(1-\pi) / R$ is matched to an average actual ratio; given the values of $R$ and $\delta$, this equality can be used to solve for $\pi$. The steady-state amortization rate $\phi$ is matched to an average repayment rate. Given the interpretation of the model's durable goods stock $S_{t}$ as homes and vehicles, the values of these parameters are computed as weighted averages of estimates for mortgages and car loans.

The calibration of $\pi$ and $\phi$ involves the basic issues of choosing the sample period for each of the model's regimes and the type of data required. The discussion of the institutional background in Section 2 provides guidance for these choices.

The sample period are determined as follows. For the high-requirement regime we use observations through 1982, given that the timing of the Garn-St.Germain Act in October of that year. We presume that immediately following deregulation the equity constraint is not binding because of the large size of home equity that is cashable at that time. Because it is much easier to read equity constraint parameters from data generated under a binding constraint, we do not use observations immediately following 1982 to calibrate the postreform regime. According to Table 1, the effective down payment on mortgages and the

\footnotetext{
${ }^{9}$ The source is "Fixed Assets and Consumer Durable Goods in the United States, 1925-1997." The service life of 1-4 units residences is 80 years. Automobiles' service life of 8 years is inferred from the reported nonlinear depreciation profile. We used the weights 0.75 and 0.25 , which are the shares of the owner occupied residential stock and consumer durable goods stock in the 1954-2004 sample.
} 
percentage of mortgages refinanced stabilize around 1995. This and the stabilization of the debt/asset ratio around the same time - See Figure 3 below - both suggest that by then the equity constraint binds again. Hence, we use observations from 1995 onwards to calibrate the low-requirement regime.

As discussed in Section 2, data on individual mortgages have little relevance after deregulation: Loan-to-value ratios may not reflect initial equity shares because of the possibility of more than one mortgage, and maturities are likely to be extended later by refinancing. Hence, we proceed as follows. For car loans, we use observations on down payments and loan maturities in car loan contracts, which we assume reflect actual equity requirements in the two sample periods. For mortgages, we use data from the Survey of Consumer Finances, as reported in Section 2. The initial equity share for homes is computed as the average equity share of households that purchased their homes within 12 months of the interview date. Because maturities reported at the interviews do not take into account the likelihood of future refinancing, calibrating $\phi$ for the low-requirement regime necessitates an alternative procedure. We set $\phi$ for this regime so that the model's increase in the debt-to-asset ratio across regimes equals the actual change from the pre-1983 sample to the post-1995 sample.

Additional details about calibration of $\pi$ and $\phi$ are presented in Appendix A. The resulting values are 0.16 and 0.0315 for the high-requirement regime, and 0.11 and 0.0161 for the lowrequirement regime.

The remaining parameters are $\theta$ and $\omega$. We chose these simultaneously to match an average share of hours worked of 0.3 and the average share of durable goods expenditure, 0.21 , in total households' expenditures in the 1954:I-1982:IV sample. ${ }^{10}$ Given the other parameters, including the $\pi$ and $\phi$ values for the pre-reform regime, the unique values of $\theta$ and $\omega$ that replicate these observations are 0.37 and 1.95. Table 2 summarizes the calibrated parameter values.

In addition to lowering down payments on new loans and extending repayment of old loans, the reduction of equity requirements enables immediate additional borrowing based on accumulated equity. This is the "borrowing shock", which is the difference between the old and the new equity share on the stock $\hat{S}$, held by the borrower in the initial steady state. This difference equals

\footnotetext{
${ }^{10}$ To calculate this ratio, we adjusted the NIPA's nondurable personal consumption expenditures by subtracting the imputed service flow of housing. We then added residential investment to personal consumption expenditures on durable goods.
} 


\begin{tabular}{l|cccccccc} 
Equity Requirement & $\pi$ & $\phi$ & $\alpha$ & $\delta$ & $\tilde{\beta}$ & $\hat{\beta}$ & $\theta$ & $\omega$ \\
\hline High & 0.16 & 0.0315 & 0.3 & 0.01 & $\frac{1}{1.01}$ & $\frac{1}{1.015}$ & 0.37 & 1.95 \\
Low & 0.11 & 0.0186 & & & & & &
\end{tabular}

Table 2: Calibrated Parameter Values

$$
\frac{\delta \hat{S}(1-\delta)}{R}\left(\frac{1-\pi^{\prime}}{\phi^{\prime}}-\frac{1-\pi}{\phi}\right),
$$

where $\pi, \phi$ and $\pi^{\prime}, \phi^{\prime}$ are the pre- and post-reform pairs of values. Given the model's calibration, this amounts to 70 percent of initial output. We assume that only half of this amount can be borrowed. ${ }^{11}$

\subsection{Transition Dynamics}

Given the calibrated parameter values, the reduction of $\pi$ and $\phi$ substantially impacts the economy's steady state. The change directly raises $\hat{B} / \hat{S}$ from 0.26 to 0.48 . The greater debt burden increases $\hat{N}$ by 4 percent and lowers $\hat{C}$ by 3 percent. The greater borrowing capacity of durable goods more than offsets the income effect from the additional debt, so $\hat{S}$ rises 2 percent. The saver's additional wealth leads to a 12 percent expansion of both $\tilde{C}$ and $\tilde{S}$.

To calculate the equilibrium path between the initial and the new steady state, we use a modified version of Fair and Taylor's (1983) procedure. We conjecture that the equity constraint does not bind for the borrower until some date $t^{*} \geq 0$ and then binds forever, and we calculate the path of prices, quantities, and Lagrange multipliers that satisfies all of the optimality and market clearing conditions. If the resulting multipliers on the constraints are all nonnegative and the households' choices violate none of the constraints, then the resulting path is the desired equilibrium. Otherwise, we search other values of $t^{*}$ until such an equilibrium path is found.

We find that $t^{\star}=30$ given the parameters' calibrated values. Figure 1 presents plots of the equilibrium path for the model's key quantities and the interest rate. The reform begins at date 0 with a one-time unexpected reduction in $\pi$ and $\phi$ and increase in $\hat{V}_{0}$ - the borrowing

\footnotetext{
${ }^{11}$ Note that this assumption does not alter the new steady state, which is based only on $\pi^{\prime}$ and $\phi^{\prime}$-along with the constant parameters of the model.
} 
$\hat{S}_{t}$
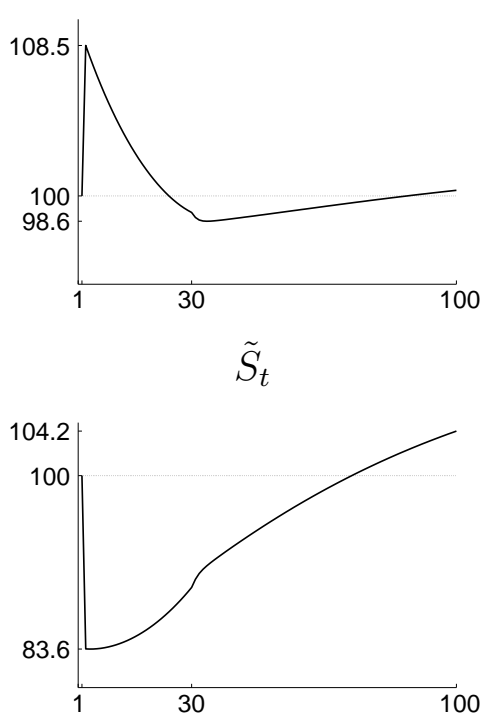

$400 \times\left(R_{t}-1\right)$

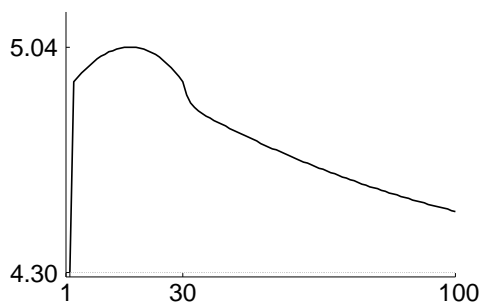

$\hat{C}_{t}$
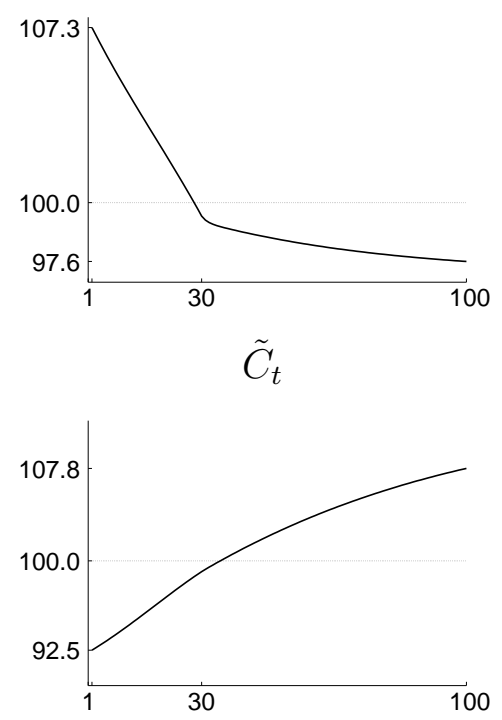

$\hat{B}_{t} /\left(\hat{S}_{t}+\tilde{S}_{t}\right)$

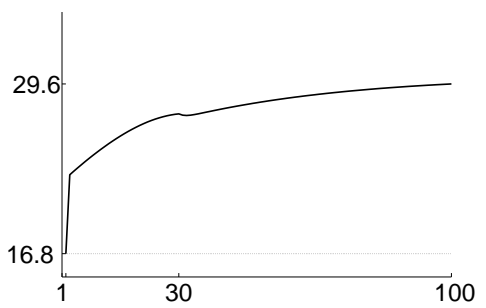

$\tilde{S}_{t} /\left(\tilde{S}_{t}+\hat{S}_{t}\right)$

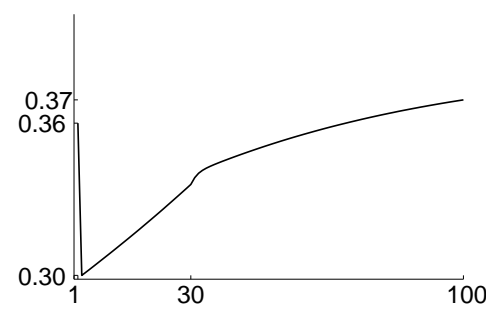

Saver's Share of Wealth

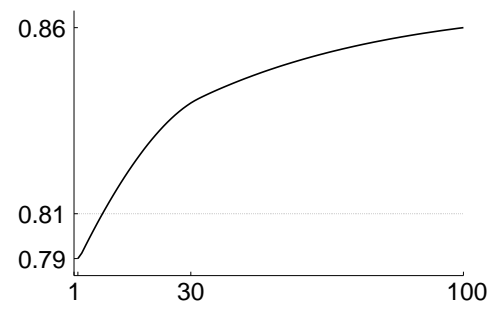

$\hat{N}_{t}$

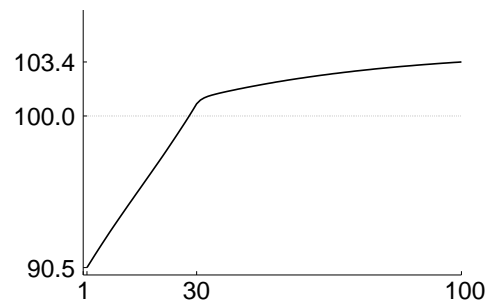

Figure 1: The Model's Equilibrium Path

All variables, except the interest rate and the shares, are expressed in percentage points relative to their initial steady-state values. Dashed lines give the initial steady-state levels. 
capacity of the durable goods' stock given the equity requirements. The sudden excess of equity over the required amount acts like a shock to the demand for loanable funds. Both the debt and the interest rate immediately jump. Later, as debt growth slows down, the interest rate gradually declines towards its steady-state value.

The interest rate jumps to a level between the two rates of time preference. ${ }^{12}$ The saver defers consumption given the temporarily high rate of interest, and, before $t^{\star}$, the borrower increases consumption of both goods and expands debt as would an unconstrained household facing a temporarily low rate of interest. The behavior of hours worked traces the borrower's nondurable consumption. Its substantial fall implies a drop in output.

The borrower's consumption pattern changes at $t^{\star}$ because then the equity constraint starts to bind again. The decline of nondurable consumption slows down, while $\hat{S}_{t}$ begins to slope up. The intuition for this upward trend can be seen using the multiplier of the equity constraint in (8),

$$
\Gamma_{t}=1-\hat{\beta} \frac{\hat{C}_{t}}{\hat{C}_{t+1}} R_{t},
$$

which reflects the value of additional funds for the borrower. After $t^{\star}$, the gradual decline of $R_{t}$ increases $\Gamma_{t}$. Because durable goods provide borrowing possibilities, their value for the borrower correspondingly increases over time. This lies behind the positive slope of $\hat{S}_{t}$ after $t^{\star}$.

The evolution of inequality in wealth and durable goods over time follows directly from the mechanism just described. Over the 25 year period shown in Figure $1, \hat{B}_{t}$ rises by 80 percent. This implies a redistribution of wealth from the borrower to the saver. This is the main force raising the saver's share of total wealth from 81 percent in the initial steady state to 86 percent after 25 years. $^{13}$

The saver's sale of durable goods to the borrower drastically diminishes inequality in durable goods following the reform: The saver's share of durable goods drops initially from 0.37 to 0.30 . However, this does not last. Over time, the inequality of durable goods holdings increases monotonically as the debt mounts.

\footnotetext{
${ }^{12}$ It is easy to show that in an endowment economy without borrowing constraints and only nondurable consumption, the households' rates of time preference bound the interest rate. Before $t^{*}$, the present economy differs from such economy in having also a fixed endowment of labor, a leisure choice, and durable consumption. However, the interest rate from this economy stays within the bounds from the simpler endowment economy.

${ }^{13}$ The saver's wealth is: stock market value $+\tilde{S}_{t}+B_{t}$; the borrower's wealth is $\hat{S}_{t}-B_{t}$.
} 
The initial small decline in the saver's share of wealth appearing in Figure 1 is caused by a stock market drop as the interest rate jumps up. The stock market value, computed as the present value of capital income, falls initially by 10.8 percent, and then slowly recuperates to approach its initial level in 25 years.

\subsection{Welfare Analysis}

With the equilibrium transition path in hand, we can calculate both households' welfare levels and compare them to their values in the initial steady state. Converting these utility differences into permanent percentage changes in both goods required to achieve the new utility level allows an interpersonal comparison of these gains. In principle a given household could lose from the reform because the terms of trade move adversely, but in fact both households benefit from the reform. The Saver's utility gain equals 2.02 percent of consumption, while the borrower's is an order of magnitude lower, 0.26 percent.

This result naturally leads one to ask why the saver's gains are so much larger than the borrower's? For this, it is helpful to decompose the borrower's utility gain into two different components. The first is the component from changing $\pi, \phi$, and $\hat{V}_{0}$ but leaving the wage and interest rate at their initial steady-state values. The borrower's gain in this experiment equals 1.35 percent of initial steady-state consumption. The equilibrium welfare gain is much less than this because of two adverse movements in the terms of trade, the persistent increase in $R_{t}$ and the long-run decrease in $W_{t}$. The short-run increase in $W_{t}$ does not offset these. All of the saver's welfare gains arise from changes in the terms of trade, so the reason that the borrower's welfare gain is so much smaller than the saver's is that the reform shifts the terms of trade against the borrower.

To better understand which price changes influence these calculations more, we calculated the transition path of an alternative model in which the saver receives an endowment of $H$ per period and the borrower operates a technology linear in labor with slope $W$. The only endogenous price in this economy is the interest rate. In this case, the reform increases the borrower's welfare by 0.45 percent of initial consumption and the saver's welfare by 1.36 percent. Apparently, the interest rate accounts for most of the welfare effects of changes in the terms of trade. 
Wealth

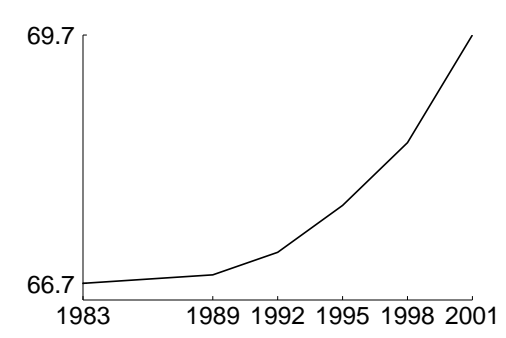

Owner-Occupied Housing

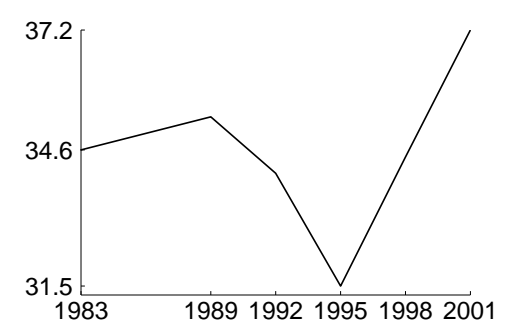

Vehicles

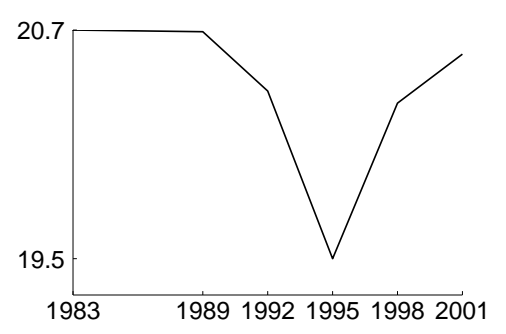

Figure 2: Ownership Shares of the Wealthiest Ten Percent of Households

All ratios expressed in percentage points.

\section{Interpretation of Macroeconomic Evidence}

In this section, we examine observations from the U.S. economy since 1983 in light of the theoretical results. The model has two novel predictions about this period: One is that the distribution of household capital becomes substantially more equal before converging to the less-equal steady state. The other is that debt growth is accompanied by high interest rates. These two predictions are two interconnected aspects of the story: As borrowers increase debt to finance consumption and household capital, the interest rate increases and their share of household capital increases, both temporarily. We first use SCF data to address the evolution of the wealth distribution, and we then compare the joint evolution of interest rates and household debt in the model and in the data.

\subsection{The Distribution of Wealth and Durable Goods}

In the U.S. economy, few rich households hold most wealth. The model economy's saver stands-in for these, while the borrower represents the remaining households. Accordingly, we examine the evolution of inequality of wealth and its components by dividing households into two groups: Those in the 1st through the 9 th wealth deciles, and those in the 10th decile. The first group owes most of the debt, whereas the second owns most of the assets. In the model, this distinction is extreme. The SCF provides the household balance sheet observations required to implement this division empirically. With it, we calculate three measures of inequality: the share of total wealth owned by the wealthiest ten percent of households, those households' share of owner-occupied real estate, and their share of vehicles.

Figure 2 plots these three inequality measures. ${ }^{14}$ It is well known that the distribution

\footnotetext{
${ }^{14}$ As mentioned in Section 2 we do not report results from the 1986 SCF due to the problematic sampling
} 
of wealth has become more unequal since the early 1980's. The observations from the SCF indicate that increase in wealth concentration occurred mostly in the 1990's. Hence, if the reform of the early 1980s affected wealth inequality, this happened with a delay. To some extent, the model reproduces such a delay, since wealth inequality initially drops after the reform (due to stock-market decline caused by high interest rates) and only thereafter rises.

Regarding the other two assets, the wealthiest ten percent of households owned 35 percent of owner-occupied housing and 20.7 percent of vehicles in 1983. These shares changed little in the 1989 survey, then declined to 32 and 19.5 percent in 1995, and grew thereafter. In the 2001 SCF the owner-occupied housing share was 37 percent, while the vehicle share approached its value in 1983. The model interprets this "V" inequality shape as the allocative response to borrowers' increased demand for funds following the reform. Inequality in housing and vehicles declines first as borrowers use the new funds, while later, as the debt accumulates, the process is reversed. In the model, the drop in the saver's share of durable goods occurs immediately after the reform, so it reproduces the sequence of changes to this measure of inequality in the data but not the timing.

\subsection{Household Debt and the Interest Rate}

This paper departs from the observation that household debt rose substantially following the deregulation of the early 1980s. Figure 3 quantifies this expansion, which starts in 1983:III. Using data from the Flow of Funds Accounts, it plots the ratio of nominal household debt to the value of household capital (primarily homes and vehicles). ${ }^{15}$ The ratio grows from 0.32 in 1982 to 0.42 in 1995. The Figure's dashed line gives the ratio of mortgage debt to owner-occupied real estate, which displays virtually the same behavior. Both ratios level off during the second half of the 1990s.

In the model, a large increase in the interest rate directly follows from the borrower's additional demand for funds, and it is well-known that interest rates rose dramatically in 1983. Figure 4 quantifies this with a plot of the real three-year treasury rate. For this, we used realized inflation over the leading twelve months as expected inflation. Using the last 12 months inflation produces a very similar picture. The average real rate for the "pre-Volcker"

\footnotetext{
procedure in this survey.

${ }^{15}$ In 1961, this ratio equalled 0.32 and it grew to 0.40 by 1966 . This is the end of a long expansion of household debt following the Korean War. The imposition of Regulation Q ceilings on Saving and Loans institutions in 1966 combined with increasing nominal interest rates resulted in financial disintermediation which shows in Figure 3 as the decline in the ratio of debt to assets until 1982. See Campbell and Hercowitz (2006) for more discussion of this history.
} 


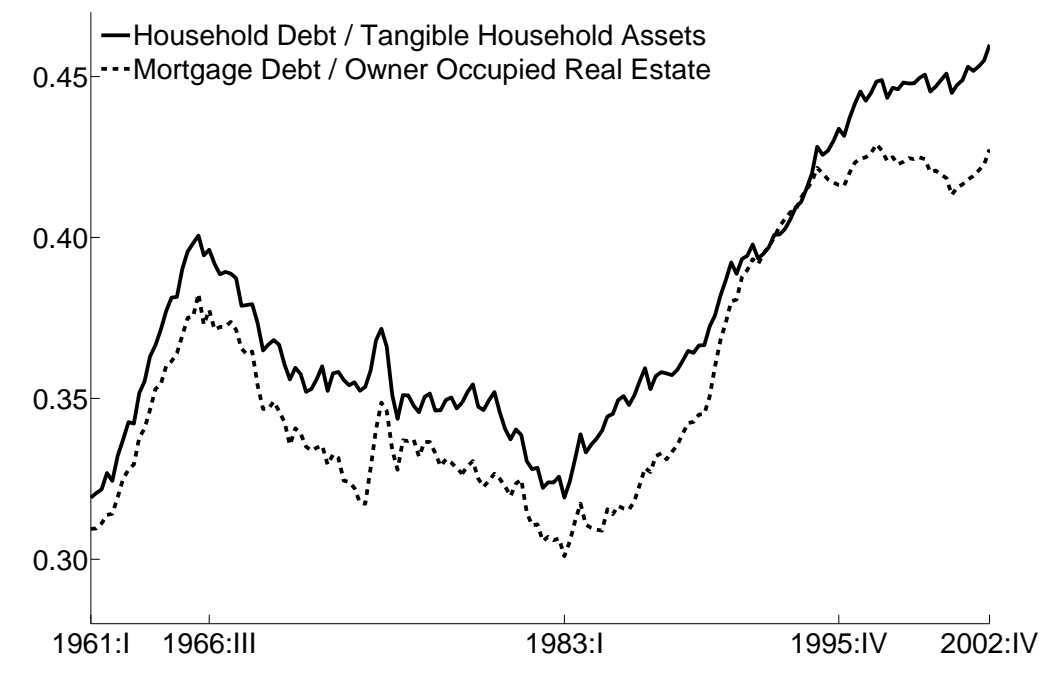

Figure 3: Ratios of Household Debt to Tangible Household Assets

period in this sample, 1961:I-1979:III, was 1.6 percent. During the Volcker monetary policy experiment, taken here to be from 1979:IV to 1982:IV, the real rate jumped to an average of 6 percent. After the peak of 10.3 percent in 1981:3, the easing of monetary policy was followed by a sharp decline in the real interest to the 5 percent level in 1983. In 1983:IV, with a lag of only one quarter after the beginning of the debt/asset ratio increase in Figure 3, the real rate starts to soar again. On average over the 1983:1995 period, which corresponding to the rapid expansion of household debt, the real rate is 4.40 , which is much higher than in the pre-Volcker era and the post-1995 period.

The model's comovement of the debt/asset ratio and the interest rate in Figure 1 provides a straightforward interpretation to the behavior of actual variables in Figures 3 and 4 . The expansion of household credit demand triggered by lowering equity requirements induces an increase in interest rates in order for savers to be willing to supply those funds.

Contemporaneous macroeconomic observers attributed the high real interest rates from 1983 through 1986 to expansionary fiscal policy. The fourth of Friedman's (1992) lessons from the Reagan deficits is

Greater deficits did result in, or at least coincide with, higher real interest rates. (pp. 301)

Similarly, Blanchard (1987) wrote 


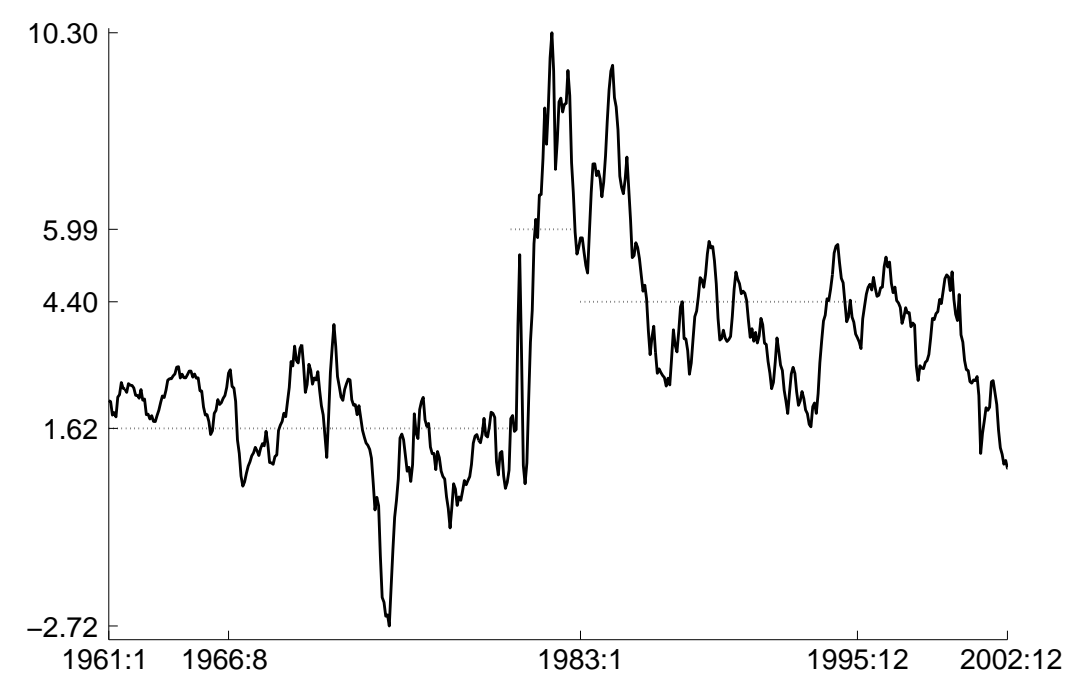

Figure 4: Three-Year Real Treasury Constant Maturity Rate

The Three-Year Treasury Constant Maturity Rate from Federal Reserve Release H.15 minus realized annual inflation using the chain-type deflator for Personal Consumption Expenditures other than Food and Energy.

By the end of 1982, budget deficits had become the dominant macroeconomic force. Large deficits were strongly increasing aggregate demand and putting pressure on interest rates. (pp. 27)

The growth of household debt after 1982 and our theoretical analysis suggest that increased demand for private credit substantially contributed to this period's high interest rates. If this was not the case (i.e., the only cause of the high interest rates was the government deficit) this should have led to a crowding out of household debt rather than the dramatic increase which actually took place.

On the calculated transition path, the interest rate immediately rises about 0.9 percent. It is of course hard to say how much of the actual interest rate increase in 1983 was caused by additional borrowing demand (private or public), but it certainly exceeds the calibrated model's prediction. However, from the discussion in Section 5, the equilibrium interest rate movements were confined between the two households' rates of time preference. With this in mind, we experimented with the borrower's rate of time preference. Raising it from the 6 percent annual rate in the calibrated model to 12 percent raises the initial interest rate jump from 4.9 to 6.5 percent. Increasing the borrower's rate of time preference further to 18 percent increases the initial interest rate to 7.5 percent. These results indicate that the 
interest rate change in the model can be quite large if the two households' rates of time preference differ enough.

\section{$7 \quad$ An Extension with Irreversible Investment}

In Section 5, one of the counterfactual results was the large overnight transfer of durable goods from the saver to the borrower. Here, we constrain each of the households to disinvest household capital no faster than it depreciates. That is

$$
\hat{X}_{t} \geq 0, \quad \tilde{X}_{t} \geq 0
$$

We intend the constraints in (23) to reflect the difficulty of converting durable goods demanded by wealthy households (mansions) into durables more useful for the middle class (2-bedroom houses). We next spell out how this constraint changes the model, and we then describe the transition of the modified economy.

\subsection{Utility Maximization}

We solve the model using the following conjectures about the equity and irreversibility constraints. We verify that these hold good for the calculated equilibrium path.

- As in the basic model, the equity constraint binds for the borrower on and after some date $t^{\star} \geq 0$.

- The irreversibility constraint binds for the saver until some date $t^{\star \star}>0$. We conjecture so because high interest rates generated by the additional borrowing demand should induce the saver to substitute away from durable goods. This effects weakens as the interest rate falls, so the constraint should eventually become slack.

- The irreversibility constraint never binds for the borrower. Immediately following the reform, the borrower wishes to increase its durable stock, and we expect the later decline in the desired stock to occur gradually enough to not violate (23).

Given these conjectures, only the saver's problem changes. Denoting the Lagrange multiplier on the irreversibility constraint with $\Omega_{t} \Upsilon_{t}$ (where $\Upsilon_{t}$ is, as previously, the multiplier of 
the saver's resource constraint). With this, the first-order condition for the Saver's optimal choice of $\tilde{S}_{t+1}$ is now

$$
1-\Omega_{t}=\tilde{\beta}\left[\frac{\Upsilon_{t+1}}{\Upsilon_{t}}\left(\frac{\theta}{1-\theta} \frac{\tilde{C}_{t+1}}{\tilde{S}_{t+1}}+(1-\delta)\left(1-\Omega_{t+1}\right)\right)\right] .
$$

When the irreversibility constraint binds $\left(\Omega_{t}>0\right.$, ), the shadow price of durable goods for the saver declines to induce the saver to slow down disinvestment.

Before considering the equilibrium path with this constraint, it is worth emphasizing that the constraints in (23) do not rule out all trade in durable goods. We think of the representative saver and borrower as stand-in's for a large number of similar households. In a slightly extended version of the model, two savers can trade installed household capital at the price of $1-\Omega_{t}$. What the constraints do eliminate is any large and sudden reallocation of household capital from savers to borrowers.

\subsection{Transition Dynamics with Irreversible Investment}

Figure 5 presents plots of the equilibrium path analogous to those in Figure 1 in Section 5. Overall, the same mechanism also operates here: The borrower issues debt to the saver to expand consumption and this raises the interest rate. Adding the irreversibility constraint changes two specific aspects of the story. The first follows directly from the friction introduced: The initial reduction of $\tilde{S}_{t}$ and initial increase of $\hat{S}_{t}$ are gradual now rather than immediate. The calculated value of $t^{\star \star}$ is 17 , so for four years after the reform, $\tilde{X}_{t}=0$. When the irreversibility constraint ceases to bind, both durable goods stocks switch directions. The limit to the saver's disinvestment also slows down the borrower's deaccumulation of equity. Accordingly, the equity requirement does not limit the borrower's debt until $t^{\star}=33$ quarters after the reform.

The second aspect follows from the typical amplification of price movements when quantities are slow to adjust. The limit on the saver's ability to generate loanable funds by selling household capital amplifies and sharpens the interest rate increase: Immediately after the reform the interest rate jumps directly to it's peak, 5.6 percent-rather than peaking later and at a lower rate, 5.0 percent, as in Figure 1. The sluggish quantity behavior shows also in the debt's initial surge, which lasts $t^{\star \star}$ periods now, rather than one in the basic model.

A direct implication of the gradual initial changes in $\tilde{S}_{t}$ and $\hat{S}_{t}$ is the slow decline in the saver's share of durable goods during $t^{\star \star}$ quarters. Hence, inequality in durable goods declines gradually for about 4 years, and only then it starts to increase due to wealth redistribution. 
$\hat{S}_{t}$
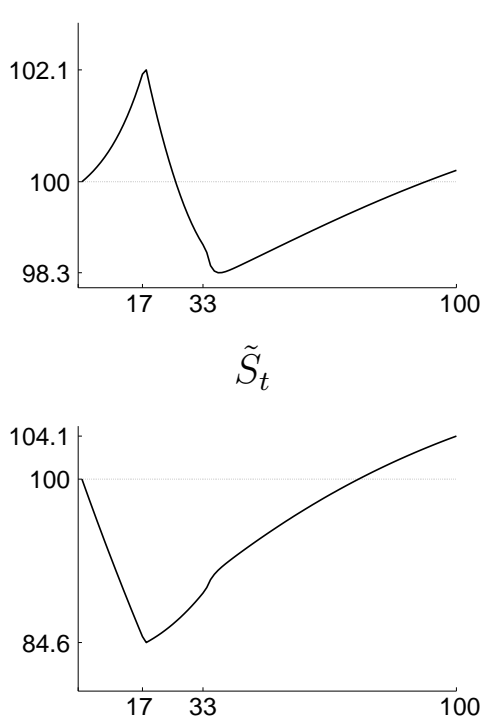

$400 \times\left(R_{t}-1\right)$

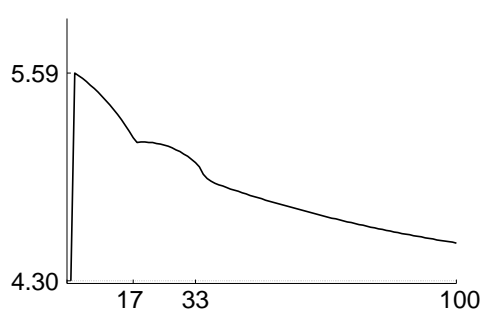

$\hat{C}_{t}$
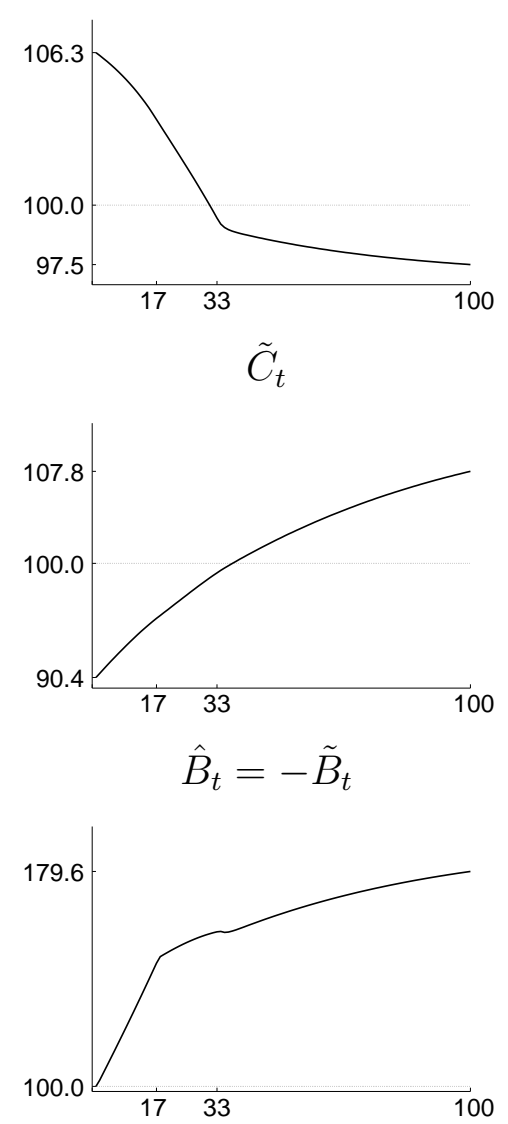

$\tilde{S}_{t} /\left(\tilde{S}_{t}+\hat{S}_{t}\right)$

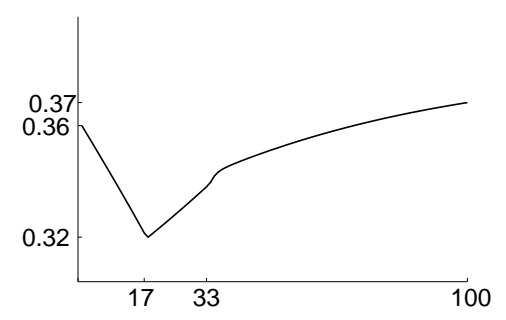

Saver's Share of Wealth
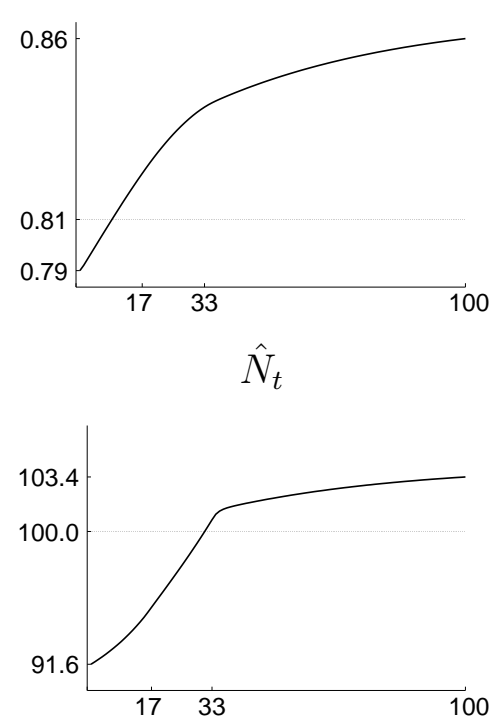

Figure 5: The Equilibrium Path with Irreversible Investment ${ }^{(i)}$

(i) All consumption variables expressed in percentage points relative to their initial steady-state values. Dashed lines give the initial steady-state values. 
The stock market and the saver's wealth share in Figure 5 behave very similarly as in Figure 1. The only noticeable difference is that the initial drop in the stock market value is more pronounced here, 12.5 percent instead of 10.8, due to the sharper interest rate hike.

\section{Concluding Remarks}

We contrast in this paper the transition of a calibrated model economy after a realistic reduction of equity requirements on households with the evidence since the early 1980s.

A key feature of the model's transition is the prolonged increase in household debt accompanied by high interest rates. This positive comovement reflects the effects of the borrowing shock triggered by allowing previously equity constrained households to cash out part of their equity. The distributional counterparts of this process are the long-run increase in the saver's share of wealth (reflecting the borrower's rising debt), and the non-monotonic behavior of the saver's share of durable goods. This share declines first, and only later it increases to a higher level than the initial one. More debt allows the relatively impatient households to increase their share of durable goods during the first stage of the transition. Due to the mounting debt, however, the borrower's share of durable goods should eventually decline.

These results are quantitatively similar to the actual evolution of the wealth distribution in the United States since 1983 as well as the actual comovement of household debt and interest. Hence, the model provides a simple interpretation of these facts, connecting them into one phenomenon.

The model's large overnight decline of hours worked following the reform is obviously counterfactual. The model's result is driven by the fact that the newly additional funds make it possible for borrowers to immediately increase consumption and leisure. Modelling the access to new borrowing as gradual process extends the decline in hours worked over a period. The resulting downward trend in hours is also counterfactual for the period starting in 1983. Modelling the initial state as a recession was another possibility we tested. Given that the U.S. economy was at the through of a deep recession at the reform, the recovery dynamics could in principle offset the decline in hours generated by this model. Quantitatively, however, this effect did not reduce dramatically the decline in hours.

The behavior of hours in the model, in which labor supply is standard, suggests the relevance of indivisibilities and frictions in employment. For example, suppose that households pay quadratic costs of adjusting hours worked. Such convex costs are relatively unimportant for the small hours adjustments in business cycles, but they can be much more significant for 
large changes such as that beginning the transition to high household debt. We examined the impact of adjustment costs on our results in an extreme way by fixing the borrower's hours worked. The simulation results in this setup were very similar to those presented here, so we expect the results to survive other more empirically relevant modifications to the labor market primitives.

The present model can be extended in different directions to address additional aspects of the link between financial reform and macroeconomic behavior observed in the U.S. since the 1980 s.

Endogenous capital accumulation is a basic extension of the model. In such an extension, we expect the initial surge in borrowing to depress productive investment. This, due to high interest rates as well as low marginal productivity of capital when hours worked decline. Over time, as hours worked trend up, the marginal productivity of capital should increase, so the productive capital stock should rise above the initial level.

Endogenizing the capital stock will also have implications for the behavior of factor prices and thus welfare results. For example, in the present setup, the wage declines when approaching the new steady state - because the capital/labor ratio declines. With a variable capital stock, the wage rate in the two steady states will be the same, and hence one of the saver's benefits and borrower's costs from the reform will disappear.

The link between credit policy and housing prices is another route to explore. For example, a fixed factor like land would generate curvature in the transformation of output into housing. During the early stages of the transition, two opposite forces would affect housing prices: The borrower's demand for housing is higher due to his newly available credit, while the saver's demand is lower given high interest rates. Hence, the relative price movement is not clear a priori. In the long-run, however, reducing equity requirements should raise the relative price of housing because of the effective reduction in the cost of credit. 


\section{Appendix}

\section{A Calibration of the Equity-Requirement Parameters}

The calibration of the pre-reform values of $\pi$ and $\phi$ proceeds as follows. For automobile loans, we use the Federal Reserve Statistical release G.19, which reports average loan-to-value ratios and repayment periods for automobile loans from 1971 onwards. Over the 1971-1982 sample, the average loan-to-value ratio is 0.87 and the average term is 13.4 quarters. For mortgage loans, the calibration is based on the Survey of Consumer Finances. The SCF includes the year of home purchase, the equity stake in the home and the original maturity of the first two mortgages. Our basic measure of the initial equity share for homes is the average equity share of households that purchased their homes within 12 months of the interview date, and borrowed at least half of the home's value. In the $1983 \mathrm{SCF}$, there are 104 such homeowners. Their average equity share is 0.2275 with a standard error of 0.0137 . For the same sample, average mortgage maturity and its standard error are 85.5 and 3.8 quarters.

Because the 1983 SCF immediately followed the Garn-St. Germain Act, we think of these terms as representative of mortgage terms at the time of the reform. To check whether they are typical for the period prior to the reform as well, we examined trends in average mortgage terms before 1983, as reported in the Federal Home Loan Bank Board's Monthly Interest Rate Survey. This survey covers single-family homes only; hence, it is more restrictive than the SCF. This survey reports stable loan-to-value ratios from 1963, the first available observation, until 1982. Thus, the average initial equity share from the 1983 SCF of 0.2275 appears to be a good estimate for the pre-reform period. In contrast to the stability of the loan-to-value ratio, the average repayment period increased from 85.2 quarters in 1963 to 102.4 in 1982 . This increase indicates that average mortgage duration in 1983 was higher than the typical duration for the period of interest. Hence, we adjust the 85.5 quarters measure from the 1983 SCF downwards by subtracting half of that increase. The resulting loan period is 76.9 quarters.

We measure mortgage and automobile debt repayment rates with the inverse of their period-average terms to maturity, and then calculate $\phi$ as the weighted average of these rates. The weights are the average shares of mortgage debt and consumer credit in total household debt over the 1954-1982 period, that is 0.7 and 0.3 . The resulting value of $\phi$ is 0.0315 . 
Similarly, $\pi$ is a weighted average of the initial equity shares from automobile and mortgage debt. Ideally, the weights should reflect the flow of loans used to purchase new automobiles and homes. As such observations are not available, we construct the weights indirectly. In a steady-state version of the model with two durable goods, loans extended in each category should equal the principle repayment rate multiplied by the category's steady-state debt. Given the repayment rates and debt shares used to calibrate $\phi$ for the period before 1983:I, the implied shares of home and automobile loans in total loans extended are 0.29 and $0.71 .^{16}$ The resulting value of $\pi$ for the high-equity requirement regime is 0.16 (the weighted average of 0.2275 for homes and 0.13 for automobiles).

For the post-reform values of $\pi$ and $\phi$ use observations from 1995 onwards, when debt/assets ratios stabilize.

The value of $\pi$ is calculated similarly as for the pre-reform period. The average loan-tovalue ratio for automobiles in the 1995:I-2004:II sample is 0.92. The average equity share of new home owners in the $1995 \mathrm{SCF}$ and the 2001 SCF are 0.1756 and 0.1749 - with the standard errors 0.0090 and 0.0094. There are 334 and 251 new homeowners in these two surveys. We use the average of the two years' observations as our measure of the mortgage down-payment rate. The average initial equity shares for both automobiles and homes decline by 0.05 from the pre- to the post-reform period. Hence, we set the value of $\pi$ for the latter period equal to 0.11 .

The post-reform value of $\phi$ is much more problematic to estimate. Because the financial reform substantially widened the options for refinancing and home equity loans, the terms of the initial mortgages ceased to represent the actual equity requirements. One possibility for evaluating $\phi$ is to assume that the terms of automobiles loans still represent actual equity constraints, and for homes, refinancing and equity loans make it possible to extend the loans' terms to the entire life of the home. The latter assumption implies that the mortgage repayment rate equals the home's depreciation rate. Computing $\phi$ in this way causes the debt/assets ratio to increase too much relative to the data. Hence, we set $\phi$ based on the actual change in the debt/asset ratio from the 1954-1982 sample average of 0.34 to the 19952005 sample average of 0.45 . Given the other parameter values, for the model to reproduce this 11 percentage point increase in the debt/asset ratio across steady states, the value of $\phi$ has to decline from 0.0315 indicated above for the pre-reform period to 0.0186 .

\footnotetext{
${ }^{16}$ The weight for home loans is computed as $(0.70 / 76.9) /((0.70 / 76.9)+(0.30 / 13.4))=0.29$, where $0.7 / 76.9$ is the mortgage/total debt ratio times the repayment rate of mortgages and, similarly, $0.30 / 13.4$ is the car loans/total debt ratio times the repayment rate of cars loans.
} 


\section{References}

Becker, R. A. (1980, September). On the long-run steady state in a simple dynamic model of equilibrium with heterogeneous households. Quarterly Journal of Economics 95(2), 375-382.

Blanchard, O. J. (1987, October). Reaganomics. Economic Policy 2(5), 15-48.

Campbell, J. R. and Z. Hercowitz (2006). The role of collateralized household debt in macroeconomic stabilization. Federal Reserve Bank of Chicago Working Paper.

Fair, R. C. and J. B. Taylor (1983, July). Solution and maximum likelihood estimation of dynamic nonlinear rational expectations models. Econometrica 51(4), 1169-1186.

Florida, R. L. (Ed.) (1986). Housing and the New Financial Markets. Rutgers, The State University of New Jersey.

Friedman, B. M. (1992, May). Learning from the Reagan deficits. American Economic Review 82(2), 299-304.

Green, R. K. and S. M. Wachter (2005, Fall). The American mortgage in historical and international context. Journal of Economic Perspectives 19(4), 93-114.

Kiyotaki, N. (1998). Credit and business cycles. Japanese Economic Review, 18-35.

Krusell, P. and A. A. Smith (1998, October). Income and wealth heterogeneity in the macroeconomy. Journal of Political Economy 106(5), 867-896. 